\title{
The Future Prospects of Dental Graduates in India: A Review
}

\author{
Zeba Siddiqui ${ }^{1}$, Rahul Srivastava ${ }^{2}$, Vriti Kohli ${ }^{3}$ \\ ${ }^{1}$ Consultant Dental Surgeon, ${ }^{2}$ Reader, Oral Medicine and Radiology, ${ }^{3}$ Under Graduate Student, Rama Dental College Hospital \\ and research Centre, Kanpur, India
}

Corresponding author: Zeba Siddiqui, Plot No 52 116/630 Bageecha Basheer Krishnapuri Rawatpur Kanpur, India

DOI: 10.21276/ijcmsr.2018.3.2.37

How to cite this article: Zeba Siddiqui, Rahul Srivastava, Vriti Kohli. The future prospects of dental graduates in India: a review. International Journal of Contemporary Medicine Surgery and Radiology. 2018;3(2):B156-B160.

\section{A B S T R A C T}

The key aim of this article is to express the personal perspective about the changing picture of the scope of dental surgeons and future of noble health profession "Dentistry" in the country India. As, we are about step into the next decade, there lies an urgent need to analyze the dental work force of the country and to study the scope and future of dentistry in the coming years.

In present time there are great deals of issue behind the dental graduates being in crisis. The Dental Council and the government of India should think of a solution to the problem of unemployment among dental surgeons in India. If this circumstance proceeds with it will prompt a negative impact on the integrity of the dental profession and highly trained dental manpower of the nation will go in vain.

Key word: Dental surgeons, Dental council, Government

\section{INTRODUCTION}

In 1920, Dr. Rafiuddin Ahmed found the first dental institution "Dr. R Ahmed Dental college" in Calcutta/West Bengal state in India followed by establishment of Bengal Dental Association, which later was recognized as Indian Dental Association. This embryonic dental institution has well established the meaning of need for dental institutions in the country, subsequently government supported to set up new government aided dental colleges in various states of India. Due to the population growth and need for dentist in the nation to serve the people, the Indian government has taken steps to bridge the dentist and general population gap by allowing private dental institutions in the country since the year 1950. ${ }^{[1]}$

\section{Statistics of bachelors in dental surgery (BDS) in India}

Recent published report suggests as follows: ${ }^{[1]}$

- In year 2000 from 309 dental colleges, the approximate count of under graduate dental students was 26,000 per year.

- With about 309 dental colleges in the country, in the year 2000 an approximate count of graduating dental students was 26,000 every year.

- In 1970, only 8000 students graduated per year.

- In urban India there was one dental practitioner for every 10,000 individuals in 2004; however, there was just a single dental practitioner per 2.5 lakh in rural India.

- The number of dental surgeons went up to as high as 30 , 570 in 2010.

- It is likely in 2020, that India has an excess of around 1 lakh dental practitioners in the country. ${ }^{[2]}$

Current data suggests that 117,825 registered dental surgeons were observed in India. ${ }^{[1]}$ It can be suggested that approximate ratio of dental graduates from private and government set up, since first established year to the present decade showed a marked raise and attained a dentist to general population ratio as $1: 10 .{ }^{[3]}$

\section{OPINION OF DIGNITARIES ABOUT THE ISSUE}

"Over the years, we have created a huge manpower of dentists and job avenues have shrunk. There is not much opportunity for today's pass outs, except if they want to start their own practice, which too isn't easy. It needs money, space, infrastructure and the right attitude", said former acting president of DCI, Dr. Mahesh Verma. ${ }^{[2]}$

\section{Causes behind the current crisis}

There are several factors that have prompted the present crisis among dental graduates. Some of these factors are:

1. Lack of interest in dental practice.

2. Uneven distribution of dental colleges.

3. Geographical Factors.

4. Lack of Government jobs.

5. Difficulties related to private practice.

6. Lack of oral health awareness in Indian public.

7. Lopsided specialist training in dentistry.

8. Lacking Dental auxiliaries.

9. Health care expenditure.

10. Quackery- stigma to dental profession in India. ${ }^{4}$

\section{LACK OF INTEREST IN DENTAL PRACTICE}

Earlier the dental admissions in dental colleges in India were 
through three ways. State-administered entrance exams, common all-India entrance and private school-administered entrance exams. The students who excel in these entrance exams mostly take admissions in MBBS whereas admissions in BDS and other paramedical degrees are usually the options available to lower ranks in the exam. So way most of the BDS admissions are not by decision and this leads to absence of enthusiasm in the dental practice. ${ }^{[4]}$

\section{UNEVEN DISTRIBUTION OF DENTAL COLLEGES}

In India there are numerous dental colleges. However, the distribution is uneven (Table 1). The current data suggests that among 117,825 registered dental surgeons approximately 90,000 were identified collectively from the state dental registries of four southern states in India (Andhra Pradesh, Karnataka, Kerala, and Tamil Nadu) and surprising to know that 25 states, 7 union territories have only 27,825 registered dental surgeons. ${ }^{[1]}$

Consequently in such states there are higher chances of pursuing BDS/MDS for students than those of states which are lacking such colleges. Also, a number of private dental colleges are sub-standard and lack the basic infrastructure. ${ }^{[4]}$

\begin{tabular}{|l|c|c|c|}
\hline States & $\begin{array}{c}\text { Number of } \\
\text { colleges }\end{array}$ & $\begin{array}{c}\text { Recognized } \\
\text { seats }\end{array}$ & $\begin{array}{c}\text { Approved } \\
\text { Seats }\end{array}$ \\
\hline Karnataka & 45 & 2800 & 250 \\
\hline Maharastra & 35 & 2030 & 990 \\
\hline Uttar Pradesh & 31 & 1680 & 1200 \\
\hline Andra Pradesh & 21 & 1380 & 450 \\
\hline Kerala & 16 & 360 & 460 \\
\hline Madhya Pradesh & 14 & 760 & 500 \\
\hline Punjab & 14 & 800 & 330 \\
\hline Gujrat & 12 & 520 & 620 \\
\hline Haryana & 10 & 660 & 200 \\
\hline Bihar & 07 & 80 & 290 \\
\hline Himachal Pradesh & 05 & 340 & - \\
\hline West Bengal & 05 & 170 & 280 \\
\hline Jharkhand & 04 & 100 & 300 \\
\hline Uttranchal & 02 & 140 & - \\
\hline \multicolumn{4}{|l|}{ Table-1: Distribution of dental colleges } \\
\hline
\end{tabular}

\section{Geographical Factors}

There has been a critical change in oral wellbeing throughout the years. There was a marked improvement between the 1980 s and 1990 s, from 1:80,000 to $1: 42,500$. At present the dentist to population ratio in India is $1: 30,000 .{ }^{[5]}$ Oral health enhancements of the urban population are better as compared to rural population. $70 \%$ of graduating dental understudies wants to build up their dental clinics in urban communities, and 30\% favored in rural regions of country. This higher fixation of dental specialists in the urban territories prompts rivalry and this opposition may likewise prompt various social and conduct issues in dental practitioners, as contribution in deceitful and degenerate practices. As per World Health Statistics - 2014, the dentist to population ratio is $1: 10000$. In the year 2004, India had one dental specialist for every 10000 individuals in urban areas and one dental specialist for each 1.5 lakh individuals in the rural regions. ${ }^{[4]}$

\section{Lack of Government Jobs}

Records show that only 5\% graduated dentists are working in the government sector. Besides, the salaries in these Government hospitals vary a lot among various parts of the country. Additionally, the selection process for such posts may likewise be dominated by the developing defilement and acts of neglect. ${ }^{[4]}$

The creation of dental surgeons post at the level of Primary Health Centers or Community Health Centers is only the solution. ${ }^{[1]}$ 1,043 dentists were posted at the PHC level in various rural areas in 1986 . Thus not even 20 percent of the existing primary health centers in India have the services of a dentist available for the population. Also, there are no set criteria for posting a dentist at the PHC level in rural areas around the country. ${ }^{[5]}$

\section{Difficulties Related To Private Practice}

Most of the dentists also resort to private practice in their own clinics. In any case, opening a private setup requires a solid speculation. Indeed, even after such money related imperatives the private practice isn't simple because of saturated market and competition now a day.

Additionally, unawareness regarding oral health pushes these clinics to be moved in urban areas and not in rural areas where these clinics are usually not successful. ${ }^{[4]}$

\begin{tabular}{|l|l|}
\hline 1 & Perception of dental treatment to be painful. \\
\hline 2 & Widespread prevalence and role model for oral health. \\
\hline 3 & Tobacco consumption. \\
\hline 4 & Lack of elementary education of oral health and related information. \\
\hline 5 & $\begin{array}{l}\text { Relieve on scientifically untested traditional methods like desi nuskas as cheap and effective and keeping professional opinion } \\
\text { as ultimate step. }\end{array}$ \\
\hline 6 & Attitude of taking pills as cure of all disease. \\
\hline 7 & Longer treatment time and stressful appointments in dental clinics. \\
\hline 8 & Prevalence care not able to generate pleasant stimulus/treatment dissatisfaction. \\
\hline 9 & $\begin{array}{l}\text { Absence of knowledge of identification of health related conditions like oral cancer in initial stages and value of periodic dental } \\
\text { checking. }\end{array}$ \\
\hline 10 & Expensive dental care and medicine. \\
\hline 11 & $\begin{array}{l}\text { Widespread prevalence of quacks in rural settings along with widespread misconception and false beliefs about oral diseases } \\
\text { and their treatment. }\end{array}$ \\
\hline 12 & Unbridgeable gap between traditional Indian and western system of medicine. \\
\hline
\end{tabular}




\section{Unawareness of oral health in indian public}

In our Indian culture there has been unawareness of public identification of oral fitness deterioration and wide acceptance of morbid mouths alongside with widespread prevalence of oral illnesses and lack of reasonable oral health-care services in the previous. Dental public health programmers have not been able to achieve the depth and penetration into society required to bring about the change in societal attitude.

The observations listed in table 2 made by direct experience based on practice and Living in the Indian society demonstrates a pressing requirement for ideal public awareness among Indian community. ${ }^{[6]}$

\section{LOPSIDED SPECIALIST TRAINING IN DENTISTRY}

The dental graduates are facing a lot of competition to get admission to the postgraduate colleges due to the limited number of seats in government colleges.

Despite the fact that, the private dental colleges are there in the field of education however these schools charge a weighty expense for post graduate seats and are not in the scope of a large portion of the dental graduates. ${ }^{[4]}$

As per a study just 48 colleges are providing postgraduate course in dentistry. Out of these, 15 colleges (33 percent) are in Karnataka state only. The huge part of these courses are in prosthodontics and orthodontics (19 percent and 18 percent, respectively). With 32.7 percent of the Indian population in the age group of zero to fourteen years, there is a more prominent demand for pediatric dental practitioners.

Only 2 percent of the specialists are being trained in community dentistry, whereas in a country like India where the majority of the population resides in the rural areas, there is greater need for these specialists. ${ }^{[5]}$

Data obtained in 2012 specified that the total number of postgraduate seats available is just around 3000 compared to every year pass outs of 25000 dental graduates. The previously mentioned issues are only a look at the hardships faced by the dental graduates.

The absence of appropriate occupation, nonappearance of post-graduate education and perpetual rivalry in the market prompts mild to serious psychological wellness

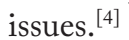

\section{LACKING DENTAL AUXILLARIES}

An increase in the quantity of dental auxiliaries should be another high priority. Since there are district hospitals with lack of dental treatment facility, dental auxiliaries should first be put in those areas.

In India there were 3,000 registered hygienists and 5,000 laboratory technicians in 1990 . This infers the administration of one hygienist was accessible to seven dental practitioners, and one laboratory technician renders administration to four dental specialists, though it ought to be a 1:1 proportion.

There are no registered dental nurses, chair side assistants and denturists. This situation is becoming critical day by day because of reduction in the quantity of schools for hygienists and laboratory technicians from forty in 1990s to twenty in 2000 with the outcome that there has been no expansion in the productivity of overburdened dental practitioners. ${ }^{[5]}$

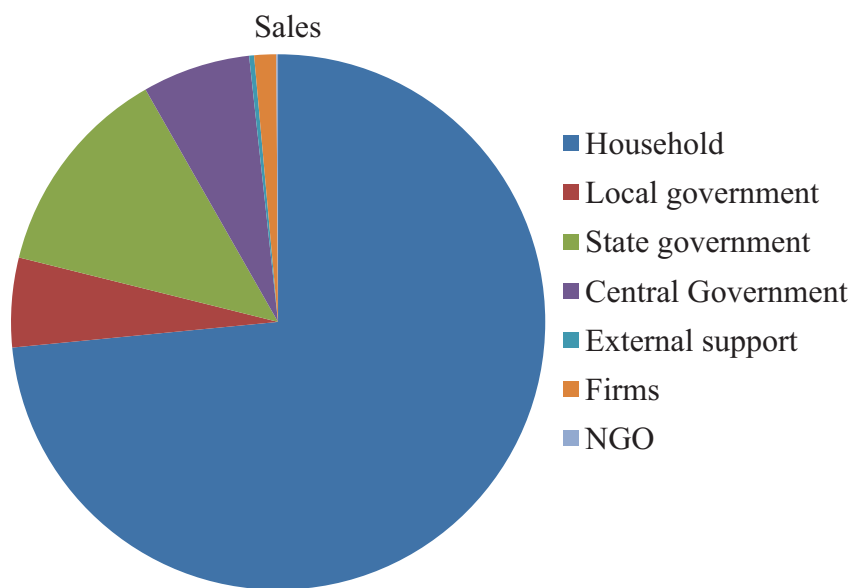

Figure-2: Statement of funds for health care in India

\section{HEALTH CARE EXPENDITURE}

The incongruity of the spending designation in India is that, out of the aggregate spending plan, the sum that is devoted to health expenditure is very meager out of this sum just a minute rate is apportioned for oral wellbeing related activities. (Figure: 2) Truth be told, there is no particular partitioned distribution for oral wellbeing in the Indian budget. India dispensed just 4.9 percent of the GDP for health-related expenditures in the last financial year, whereas other smaller Southeast Asian countries with smaller populations allocate nearly the same amount or more for health-related activities. For example, Maldives is spending 7.1 percent of its GDP on health-related activities (figure-2). ${ }^{[5]}$

\section{QUACKERY- STIGMA TO DENTAL PROFESSION IN INDIA}

Quackery in the form of street dentistry is prevalent in India and is practiced since ages. Only $15-20 \%$ of people in India are able to get dental services through national schemes. The annual per capita public health expenditure in India is no more than Rs.200.8, thus the quality of public health services available are below desirable standards. $80-85 \%$ of people are spending money from their pocket thus providing an ideal breeding ground for quackery to dental practice in India.

A number of factors have contributed to quackery in India , which include:

- Higher cost of dental treatment by professionals.

- Repeated dental appointments in the clinics.

- Lack of awareness.

- Increased competition

- Lack of dental education, illiteracy; as majority of elderly population residing in rural area is uneducated, poor accessibility to dental clinics and the failure to develop guidelines and policies for combating quackery.

There is no information available with respect to the quantity of quacks, but according to publishing data, there are around 2,500-3,000 quacks practicing dentistry in Delhi only. ${ }^{[7]}$

\section{WHAT CAN BE DONE TO OVERCOME THE CRISIS?}

There are following essential steps to control the poor circumstance of dental graduates in India. 
1. The quantity of dental college should be controlled as there are a higher number of dental colleges than the total number of post-graduate seats for dental graduates. It is very essential to control increase supply of dental manpower now as it is leading just to higher joblessness rates. If the present situation continues, there will be more than 1 lakh dentist's oversupply by the year 2020.

2. Strict action should be taken by Dental Council of India (DCI) on those dental colleges that are not up to the standards or not following DCI guidelines.

3. The DCI should conduct a single uniform entrance exam of dentistry independent of medical entrance examinations. And this dental entrance exam should not be linked to the medical admission exam. Only this way just those applicants who are extremely interested in the dental profession will apply for admission. American system of the Dental Admission Test (DAT) can be followed by DCI which is a single entrance test exists for all dental colleges.

4. The quantity of post-graduate dental seats should be increased, so that dental graduates will get more opportunities to pursue post-graduation.

5. The unevenness between the rural and urban dental practitioners can be enhanced by expanding openings for job opportunities in rural zones, in this manner the rustic regions will attract dental graduates. In this way the convergence of dental graduates in the urban zones will separate to underserved regions. The Government of India is taking an initiative to set up dental practices in rural areas by providing the subsidies, which is really essential.

6. The Government of India should plan to create new posts for dental graduates in government hospitals and at the Primary Health Centers. ${ }^{[4]}$

7. Government and Dental Council should be serious about National oral wellbeing strategy plan and portion of assets to execute these approaches. National oral healthcare programmer could be started to improve employment opportunities. Also government funded oral health research agency could employ dentists. The insufficiency in primary care services for oral health is also highlighted in Universal Health Coverage report of the Planning Commission of India, which may influence the India's ambition to have general wellbeing coverage. ${ }^{[8,4]}$

\section{THE BRIGHTER SIDE OF THE PICTURE}

However, the brighter side of the picture is reflected in

\section{Growth in dental tourism}

Nature of therapeutic and dental treatment in metropolitan cities in India is in the same class as anyplace else in the world and is accessible at significantly less expensive rates when compared with the western nations. The cost of practically identical dental treatment is $1 / 8$ th to $1 / 5$ th of that in western nations. The idea of dental tourism is picking up criticalness and near future will see a further development in dental tourism as since 2000 it has expanded more than 20 fold.

\section{Increased health care awareness}

Powerful national financial development, rising family livelihoods better financial condition, quick development in private part, expanding infiltration of medical coverage (including dental) have all made medicinal services a quickly developing private division and prompting increased health awareness.

Developing awareness has brought, expanding interest for better healthcare facilities. Numerous Indians are acquiring medical coverage. Healthcare awareness among the urban individuals is extensively higher than the rural individuals. Interest for quality social insurance at affordable costs is the normal result of this advancement.

\section{Increasing market size}

The Indian Healthcare market is at around 60 billion US\$. The business is expected to develop to 150 billion US\$ by 2017. The Indian healthcare market is one of the largest services sectors, contributing $2 \%$ to the country's GDP.

\section{High growth in domestic market}

Government has put substantial totals in healthcare services. India is among the top 5 countries that offer health services to poor in public sector. Subsidies are provided to the economically poor Financial assistance from nationalized banks is provided at $9 \%$ to $10 \%$ interest to establish private practices in rural areas.

\section{Present dental industry}

Total market for the Dental equipments and materials is evaluated to associate with 50 million US\$ every year. The potential size of India's dental market is assessed to be tremendous.

high growth in import of dental products

Another zone that is encountering enduring development is the import of dental items. India's market for dental items is amazingly dynamic, with a current assessed development rate of between 25 to $30 \%$.

\section{Health insurance}

After liberalization of economic policy, a large number of private players have entered into the Indian market. Dental health insurance also, has become a part of comprehensive health insurance cover now.

\section{Reduced import duty structure}

Government has liberalized the import policy and a uniform taxation system. Presently, the import duty is just $10.7 \%$ on $90 \%$ of the dental items and on the rest of the $10 \%$, it is $26 \%$. For Consumable dental items the dental import duty is a maximum of $28 \%$. The liberal polices of govt. has helped worldwide trading and made open doors for international dental manufacturers.

\section{World bank aid to set up infrastructure}

Indeed, even World Bank is giving money related help to create and run hospitals \& diagnostic centers in rural areas. Govt. is likewise reassuring such activities to improve health care facilities. ${ }^{[3]}$

\section{CONCLUSION}

The current circumstance of dental graduates is critical and requires radical decisions to be taken. 
The Indian healthcare industry is growing very fast owing to the increasing demand for quality healthcare. However, even in such situation the condition of dental graduates is not improving. . Although all of these factors cannot be eliminated immediately, but DCI and the Government of India should take steps to retain the interest of dental graduates within the dental stream. If appropriate decisions are not made on time, it will negatively affect the integrity of the dental profession, and highly trained dental manpower of the country will go in vain.

\section{REFERENCES}

1. S. R. B. Arwind. Future of Dentistry in India: A raise or fall? Journal of contemporary orofacial health and research. 2015;1(2):41-42.

2. Dental Council of India stops dental colleges in India. Available from http://indiatoday.intoday.in/education/ story/bds-institutes-close-com/1/670930.html

3. P. Renu, N.K. Ahuja. Demographics \& Current Scenario with Respect to Dentists, Dental Institutions \& Dental Practices in India. Indian Journal of Dental Sciences. 2011; 3(2):8-11.

4. Y. Sankalp, R. Gautam. The current status of Dental graduates in India.

5. Available from http://www.panafrican-med-journal. com/content//article/23/22/full/

6. T. Shobha. Challenges to the Oral Health Workforce in India. Journal of Dental Education. 2004; 68:28-33.

7. S. Pritma, B. Afshan, Gupta N.D. Dental Health attitude in Indian Society of Preventive \& Community Dentistry.2013;3(2):81-84.

8. K.D. Suruchi, C.S. Amarjit, S. Anupriya, S. Naveen, S. Sangeet, S. Vandana. Quackery: A stigma to Dental Profession. Journal of Dental Herald. 2015; 2(4):12-14.

9. S. Kamal. Future of Dental graduates in India. Journal of Applied Dental and Medical Sciences. 2016; 2(3). Available from file:///C:/Users/SONY/Downloads/ article_1476284405\%20(1).pdf

Source of Support: Nil; Conflict of Interest: None

Submitted: 20-05-2018; Accepted: 21-06-2018; Published online: 02-07-2018 